\title{
Combining Activity Theory and Grounded Theory for the Design of Collaborative Interfaces
}

\author{
Christine Rivers, Amy Tan, Janko Calic, \\ I-Lab Multimedia and DSP Research Group, \\ Centre of Communications Systems and Research \\ University of Surrey, Guildford, GU2 7XH, United Kingdom \\ \{c.rivers, j.calic\}@surrey.ac.uk, \{amy.tan@ntu.ac.uk\}
}

\begin{abstract}
In remote tabletop collaboration multiple users interact with the system and with each other. Thus, human-computer interaction and humanhuman interaction exists in parallel. In order to improve remote tabletop systems for multiple users both levels have to be taken into account. This requires an in-depth analysis of both levels achieved by qualitative analysis. In this paper we illustrate how a combination of activity theory and grounded theory can help researchers and designers to improve and develop better collaborative interfaces.
\end{abstract}

Keywords. Activity theory, grounded theory, remote tabletop collaboration, methodological-design approach

\section{Introduction}

The increasing use of collaborative technologies, in particular remote tabletop groupware has provided a fertile ground for research, specifically for user interface design. Most studies concerned with user interface design focused on humancomputer interaction (HCI) $[1,2,3]$. We define HCI as the first level of remote collaboration. This first level focuses on single user interaction. However, in remote collaboration multiple users can interact with the system and with each other. The latter is understood as human-human interaction (HHI). We claim that both levels, $\mathrm{HCI}$ and $\mathrm{HHI}$ have to be studied to understand, improve and develop existing and new interfaces suitable for multiple users in remote collaboration.

The investigation of both levels at the same time is a complex process and requires in-depth analyses. This can be time-consuming and expensive, as more researchers are needed for this undertaking. Mixing methods might be a viable solution to overcome these problems of complexity and can be beneficial rather than contradictory [4]. We believe that the combination of two qualitative approaches, activity theory $[5,6,7]$ and grounded theory $[8,9,10,11,12]$ is suitable to address these issues. An earlier study, conducted in 2007 [13] already took this issue into account and the combination of qualitative content analysis and grounded theory has been tested. Even though, mixing grounded theory with qualitative content analysis revealed useful findings it has to be kept in mind that these findings were based on 
dyadic remote tabletop collaboration. Only two users have been analysed simultaneously, which implies that the collaborative process can still be examined by only one researcher, although a second one who either controls the findings or does the process of analysis himself/ herself would be beyond all question a good and desirable addition while analysing multiple user remote tabletop collaboration.

However, investigating multiple users interacting via a tabletop groupware might be a difficult and more challenging undertaking for one researcher. Therefore, an approach or the combination of approaches that that enables one researcher to focus on multiple users and their collaborative behaviour is needed. Due to the fact that grounded theory is commonly used to examine group behaviour and the experiences made previously with this approach, give reason to use grounded theory again. None of the other existing qualitative approaches has been found to be applicable to easily uncover collaborative aspects with the interface and among users, except Activity Theory. Furthermore, the three levels that constitute activity theory, activities, actions and operations [7], have frequently occurred during analysis beforehand [13]. Therefore, it seems worthwhile to test the combination of grounded theory and activity theory for investigating remote tabletop collaboration of multiple users.

The paper is structured as follows: The theoretical background introduces the two qualitative approaches, activity theory and grounded theory and explains the key elements. After having outlined the theoretical concepts of the approaches, we apply them and explain step-by-step how the combination can yield useful results. The section, Discussion and Findings reflects our insights gained by combining the approaches. Design suggestions regarding the improvement will be given. Lastly, we conclude, summarize and give future suggestions.

\section{Theoretical Background}

Mixing research methods in HCI to gain a deeper understanding regarding remote collaboration and the way technology is used, has been found to yield more in-depth and reliable results [14] as opposed to using one method at the time. One approach might only focus on a certain aspect and other elements will easily be missed out [15]. In this section we will discuss the use and ideal of activity theory and grounded theory which we combine to study remote tabletop collaboration of mixed presence groups ${ }^{1}$.

\subsection{Activity Theory}

Originally, Activity Theory is a cultural-historical theory founded by a group of revolutionary Russian psychologists Vygotsky, Rubenshtein, Leont'ev and Luria [7] in the beginning of the $20^{\text {th }}$ century. It is a theoretical framework rather than an analytical technique. Its interest is the explanation of social and cultural work

\footnotetext{
${ }^{1}$ The term mixed presence group refers to mixed presence groupware, which indicates that colocated and remote users working over a shared visual workspace in real time [23].
} 
practices by relating them to the cultural and historic context in which the activity is being performed [16]. These two aspects are vaguely explained within the framework. Historical, could be understood as the process taking place and the historic interaction, hence the development the users experience. Collaborative, might refer to the actual interaction, taking place between the user and the system, as well as between and among users.

Activity Theory gained popularity as an approach in $\mathrm{HCI}$ in the nineties $[5,16,17]$. Designers had difficulties identifying the nature of users problems with the system and this approach helped them to focus on the end-users activities, actions and operations $[5,7,16,17]$. Consequently, designers and researchers were able to study, deduce and interpret concepts of users needs. The user should be considered within a historical and collaborative context.

Activities, actions and operations are the three levels of activity theory [18]. These levels imply four basic principles [6]. Firstly, a hierarchical structure: activities include actions and actions require operations. Activities have motives and can be understood as series of actions. Actions are goal-oriented and part of activities. The goal is to finish the activity. Thirdly, operations are executing actions. When users start to work with a system they have to get used to the system. So, actions are carried out consciously, over time these become unconscious actions, so called operations.

The second basic principle refers to object-orientedness. Living in an objectoriented world indicates that we interact with objects and these have certain natural properties as well as cultural and social ones. Assuming that a remote tabletop also has such properties gives reason to conclude that social interaction in co-located and remote collaboration might be influenced by these properties. The third basic principle is internalization and externalization of activities. However, it is difficult to determine and distinguish between internal and external activities, because activities constantly transform from internal to external [7]. The last basic principle [6] refers to the activity as mediated by tools and these tools are transformed during the development of the activity.

Activity theory is based on these principles and understood as a conceptual framework that helps to identify actions and interaction with artifacts within a historic, cultural and social context. [19] points out that the interface can only be understood through its use in a real context and users should be analysed within the context of development. Further, the interface only becomes visible and evident when problems with the interface occur. We claim that the interface also becomes evident and visible when social interaction takes place among users interacting with the system and each other, as activities are part of social interaction.

\subsection{Grounded Theory}

The use of Grounded Theory in HCI is not uncommon, however, its use and validity has been criticized [20,12]. Traditional research relies on literature, theoretical background and formulated hypothesis [21]. We believe that preconceived hypothesis and or theories might hinder us to find concepts and unfold hidden structures of interaction. Grounded Theory is an inductive approach that investigates cases as a 
whole and theory emerges form the data anlaysed thoroughly be using three coding steps which will be considered below. Variables, as known from quantitative studies are labeled as codes, categories and concepts. Exploring and understanding the interrelationship between categories and concepts (theoretical sensitivity) is one of the main analytical processes of this approach [8, 10, 22].

Analysing data can be complex and time-consuming. Using Grounded theory means that data has to be reduced and fragmented by means of three coding processes: open coding, axial coding and selective coding. The researcher starts to reduce and fragment data by identifying, naming, describing and categorizing the data. Having established codes and categories helps the researcher to relate codes, and categories. This process is called axial coding and is a combination of inductive and deductive thinking $[9,10,21,22]$. From the reduced data a core category, a central concept will emerge. Choosing, finding or identifying this one core concept and relating all the other categories to this specific one, is understood as selective coding [22]. These insights emerge from memos, which are short documents of the researcher, field notes or code notes (theoretical notes) made additionally to the coding processes.

In the next section we will describe how we combined and applied these two approaches and gained useful results.

\section{Methodology}

\subsection{Data Source and Collection}

The data analyzed in this study was collected from three video recordings of three mixed presence groups. In June 2008 we conducted a formative experiment of mixed presence groups performing a collaborative writing task over a remote tabletop. A mixed presence group existed of four participants, two co-located users at each location (see Picture 1).



Pic. 1. Snapshot from Video 2 (Group 2): Remote tabletop collaboration of mixed presence groups 
The co-located group A had to collaborate with the other co-located group B over the shared visual workspace using an audio/video link. A digital pen and a keyboard for direct interaction have been provided at each desk location. Participants of this study were researcher from the University of Surrey (UniS) and engineers from Thales Research \& Technology UK (TRT UK).

Before the two groups met virtually, each co-located group had to write a story colocated using the same tabletop groupware. The audio/video link was turned off and the same interaction tools had been provided. Both co-located groups had to write a story based on the same pictures within 30 minutes.

The task of the remote session was to merge these two stories together and produce one new story within the same time frame. The pictures provided in the co-located sessions have been displayed, as well as the two documents with the stories. In order to write the story using the keyboard and or digital pen the users had to share a word application. The commands cut and paste were not allowed.

All sessions have been recorded and field notes have been taken during the experiment referring to the social interaction of the users and their interaction with the system. We were interested in how the remote tabletop system hindered or facilitated collaboration of mixed presence groupware in order to deduce design criteria. Based on the three video recordings and the field notes we started our analysis.

\subsection{Combining Activity Theory and Grounded Theory}

Initial observation of the data showed that the collaborative writing task prompted users to structure the task. All three mixed presence groups proceeded the same way, starting with planning, brainstorming and producing. These steps have been identified as activities. 46 Video sequences have been extracted from the main data, which referred to these activities.

As stated earlier in this chapter, activity theory is based on three levels: activities, actions and operations. Approaching the data openly, which is one of the fundamental ideas of grounded theory, allowed for recognizing the emergence of activities, instead of forcing activities to exist. Emergence rather than forcing is another very important criterion for using grounded theory. Having found these it seems to be relevant to investigate each activity separately and in-depth.

During the activity Planning users carried out verbal and nonverbal individual and collaborative actions as found in the dyadic remote groups analysed by means of grounded theory and qualitative content analysis [13]. The actions found during this activity have been categorized as seeking, viewing and preselecting. The goal of each action was to finish the activity. Executing these actions to achieve the goal has been defined as operations, which revealed the codes, see Table 1.

Table 1. Activities, Actions and Operations emerged from Group Interaction Tables

\begin{tabular}{lll}
\hline Activities & Actions (Categories) & Operations (Codes) \\
\hline Planning & $\begin{array}{l}\text { Seeking } \\
\text { Viewing }\end{array}$ & $\begin{array}{l}\text { Opening documents from file list, using digital } \\
\text { pen }\end{array}$ \\
\hline
\end{tabular}


6 Combining Activity Theory and Grounded Theory for the Design of Collaborative Interfaces

\begin{tabular}{|c|c|c|}
\hline & Preselecting & $\begin{array}{l}\text { Moving documents using digital pen } \\
\text { Arranging documents in high resolution area to } \\
\text { read } \\
\text { them both at the same time, using digital pen } \\
\text { Reading documents } \\
\text { Sharing document with word application } \\
\text { Asking if other group has read document } \\
\text { Asking if they had the same information to write } \\
\text { the } \\
\text { story } \\
\text { Assigning roles: negotiating writer }\end{array}$ \\
\hline Brainstorming & $\begin{array}{l}\text { Reviewing } \\
\text { Selecting }\end{array}$ & $\begin{array}{l}\text { Suggesting ideas } \\
\text { Scribbling notes with pen on notepad } \\
\text { Repeating content } \\
\text { Opening documents } \\
\text { Pointing at information in documents with hand } \\
\text { Pointing at information in document using the } \\
\text { pen } \\
\text { Using hand to express ideas }\end{array}$ \\
\hline Producing & $\begin{array}{l}\text { Reviewing } \\
\text { Reselecting } \\
\text { Editing }\end{array}$ & $\begin{array}{l}\text { Pointing at information in document using whole } \\
\text { hands } \\
\text { Discussion about keeping content and changing } \\
\text { content by pointing at information in documents } \\
\text { Searching document for information using finger } \\
\text { or pen } \\
\text { Using index finger to point at information in } \\
\text { document } \\
\text { Partner uses cursor of pen to translate action } \\
\text { Taking pen from co-located partner to edit } \\
\text { document } \\
\text { Giving pen to co-located partner to edit } \\
\text { document } \\
\text { Writer using keyboard to edit document } \\
\text { Co-located partner takes keyboard to edit } \\
\text { document } \\
\text { Underlining part of information to show changes } \\
\text { or important information } \\
\text { Moving documents to find information } \\
\text { Moving documents to be involved (using pen) } \\
\text { Giving writing control function to other team }\end{array}$ \\
\hline
\end{tabular}

The activity brainstorming included two actions reviewing and selecting. In order to accomplish these, different operations have been carried out, see Table 8 . The same has been found to be applicable for the last activity producing. This process of open and axial coding showed that additionally to operations, which are executing actions cognitive processes take place. Operations require the users cognitive abilities to be carried out. Based on these insights and memos used during the process of axial a core concept has been deduced (selective coding): cognitive group abilities. 
Group cognition is understood as a process and product of group interaction, as groups are informative-processing units [26]. It describes the transmission of grouprelevant knowledge and shared mental models. Unfolding group cognition can help the researcher to understand multiple users interaction in a remote tabletop environment better, hence improving existing systems due to the users cognitive needs.

The importance of cognitive group abilities in remote tabletop collaboration has been found to be relevant to all video recordings analysed in this study. Further, it was possible to link cognitive group abilities with actions and activities. Five cognitive group abilities have been identified as fundamental during remote tabletop collaboration: acquiring knowledge, categorizing information, associating information, creating meaning of information and drawing conclusions of information.

Developing a theory. Further revision of the data and focusing on the core concept revealed that cognitive group abilities were not always supported by the system, thus affected collaborative behaviour of both, co-located and remote groups. Co-located or remote collaborative behaviour has been found to occur either as an act of including the other remote group or excluding the other remote group. Based on this finding a theoretical scheme has been developed that helped understanding to what extend collaborative behaviour of mixed presence groups has been affected if the system does not support cognitive group abilities, thus operations, actions and activities.

Four types of collaborative behaviour have been determined within the theoretical scheme: excluding co-located collaborative behaviour, excluding remote collaborative behaviour, including co-located collaborative behaviour, including remote collaborative behaviour. At this point it seemed to be interesting to know how often each type occurred during remote tabletop collaboration. For this purpose the findings qualitative results have been quantified by means of analysis of frequency, see Table 2.

Table 2. Analysis of Frequency of four types of collaborative behaviour

\begin{tabular}{llllll}
\hline \multicolumn{2}{l}{ Collaborative Behaviour } & & Abbrev. & Type & Frequency \\
\hline $\begin{array}{l}\text { Including } \\
\text { behaviour }\end{array}$ & remote & collaborative & Ic re & 1 & 22 \\
$\begin{array}{l}\text { Including } \\
\text { behaviour }\end{array}$ & co-located & collaborative & Ic co & $z$ & 4 \\
$\begin{array}{l}\text { Excluding } \\
\text { behaviour }\end{array}$ & remote & collaborative & Ex re & 3 & 28 \\
$\begin{array}{l}\text { Excluding } \\
\text { behaviour }\end{array}$ & co-located collaborative & Exce & 4 & 4 \\
\hline
\end{tabular}

The two types, including and excluding co-located collaborative behaviour did not occur frequently during remote collaboration and have therefore been not included in further analysis. Interestingly, type 3 occurred more often than type 1, which indicated that the remote group has been excluded more often than included. 

Interfaces

Focusing on the two most frequently occurring types showed that these two types took place one after another, which we developed the theory that the collaborative behaviour of mixed presence groups in remote tabletop collaboration continuously transit from excluding remote collaborative behaviour to including remote collaborative behaviour and from including remote collaborative behaviour to excluding remote collaborative behaviour depending on the cognitive support a system has been designed to assist.

In order to validate this theory comparative analysis has been applied for all three cases (video recordings) focusing on the structure of transition, which revealed that all video recordings reflected the same phenomenon. Moreover, post ante personal interaction showed that participants constantly felt excluded and included at the same time during remote collaboration. These answers confirm the developed theory and also showed that combining grounded theory and activity theory can help to understand the both levels of interaction human-human interaction and humancomputer interaction. Furthermore, it helps to unfold different levels of the collaborative process: activities, actions, operations and cognitive requirements.

\section{Discussion and Suggestions}

We suggest incorporating an information management tool that supports users during remote tabletop collaboration. Such an information management tool should enhance users during the activities of brainstorming and producing and support the actions needed to accomplish the activities, individually and collaboratively at the same time. More importantly, an information management tool should support the cognitive group abilities of acquiring knowledge, categorizing information, associating information, creating meaning of information and drawing conclusions of information. If these cognitive group abilities are not supported by the system the colocated group A excludes the remote group B even if the intention of the co-located group $\mathrm{A}$ is to include the other remote group B.

A theoretical framework of such an intelligent information management tool has been introduced by [13], called the InfoManager. Although, this idea of an intelligent information management tool exists referring to Activity Theory the principle of object-orientedness has to be taken into account. Other findings of this study showed that users used different tools during certain activities. During the activity planning users interacted with the interface using the digital pen and the video link, whereas during brainstorming only the video link seemed to be important. The provided keyboard has mainly been used in conjunction with the digital pen during the activity production. This implies that a collaborative information management tool should allow users to use multiple and different kinds of direct and indirect interaction devices during remote tabletop collaboration. Moreover, this indicates that a remote tabletop groupware that facilitates multiple users input is highly eligible. 
Combining Activity Theory and Grounded Theory for the Design of Collaborative

Interfaces 9

\section{Conclusions}

In conclusion, our study showed that combining two qualitative approaches, activity theory and grounded theory, yield interesting results regarding the improvement and development of collaborative user interface design. We introduced the analytical thinking process and gave suggestions how to use findings and furthermore, how to improve the interface. The main finding was that mixed presence groups in remote tabletop collaboration transit between including and excluding remote collaborative behaviour due to the fact that their cognitive group abilities are not supported by the system.

We suggested implementing an information management tool that facilitates cognitive group abilities of mixed presence groups in remote tabletop collaboration and explained how cognitive group abilities should be supported during remote tabletop collaboration.

Although, combining these two approaches proved to be useful, further research is required to test the viability of this method specifically, using a larger sample of mixed presence groups. Additionally, implementing the proposed information management tool in an existing remote tabletop groupware would validate the outcomes and further contribute to collaborative interface design research for remote tabletop groupware.

Acknowledgement. I would like to thank Thales Research \& Technology UK for providing the remote tabletops and technical support during the experiment as well as all participants of TRT UK and UniS for their time and commitment. The work presented was developed within VISNET II, a European Network of Excellence (http://www.visnet-noe.org), funded under the European Commission IST FP6 programme.

\section{References}

1. Bailey, R. W.: Human Performance Engineering: Using Human Factors/Ergonomics to achieve Computer System Usability. Prentice Hall (1989)

2. Paay, J.: Form Ethnography to Interface Design. In: Johanna Lumsden (Ed.), User Interface Design and Evaluation for mobile Technology. Vol.1, IGI Global (2008)

3. Tarmizi, H., Payne, M., Noteboom, C., Zhang C., Steinhauser L., Vreede G-J., Zigurs I.: Technical and Environmental Challenges of Collaboration Engineering in Distributed Environments, CRIWG 2006, LNCS 4154, 38-53 (2006)

4. Monk A., Nardi B., Gilbert N., Mantei M., McCarthy J.: Mixing Oil and Water? Ethnography versus Experimental Psychology in the Study of Computer-Mediated Communication. Interchi '93. 3-6 (1993)

5. Nardi, B. A.: Context and Consciousness, Activity Theory and Human-Computer Interaction, London: MIT Press (1997)

6. Keptelinin, V., Nardi, B.A.: Activity Theory: Basic Concepts and Applications, CHI 97, (1997) http://www.sigchi.org/chi97/proceedings/tutorial/bn.htm

7. Rajkumar, S., (2000), Activity Theory, http://mcs.open.ac.uk/yr258/act_theory

8. Alsop, G., Tompsett, C.: Grounded Theory as an Approach to Studying Student's Uses of Learning Management Systems, ALT-J, Vol. 10, No.2, 63-76 (2002) 
10 Combining Activity Theory and Grounded Theory for the Design of Collaborative Interfaces

9. Charmaz, K.: Constructing Grounded Theory, London: SAGE (2006)

10. Glaser, B., Strauss, A.L.: The discovery of Grounded Theory, Chicago: Aldine(1967)

11. Linden, T., Cybulski J.L.: Application of Grounded Theory to Exploring Multimedia Design Practices, $7^{\text {th }}$ Pacific Asia Conference on Information Systems, July 2003, Adelaide, South Australia, 508-522 (2003)

12. Sarker, S., Lau, F., Sahay, S.: Using an Adapted Grounded Theory Approach for Inductive Theory Build About Virtual Team Development, The DATA BASE for Advances in Information Systems, Vol. 32, No.1, 38-56

13. Glaser C., Tan A., Kondoz A.: An intelligent information management tool for complex distributed human collaboration: In: Niiranen S., Yli-HIetanaen, Lugmayr (eds): Open Information Managemnt: Applications of Interconnectivity and Collaboration, Chapter 5. pp. 113-143(2009)

14. Ormerod R. J.: Mixing Methods in Practice: A Transformation-Competence Persepective. Journal of the Operational Research Society. Vol 59. No 1. 137-138 (2008)

15. Glaser C., Tan A., Kondoz A.: Talk-in interaction of mixed-gender and same-gender Virtual Teams reflects usability of virtual collaboration systems. In: Proceeding of the third IASTED International Conference Human Computer Interaction, pp. 291-296. Innsbruck (2008)

16. Bertelsen O.W., Bødker S.: Information Technology in Human Activity. Scandinavian Journal of Information Systems. Vol 12.3-14 (2000)

17. Engeström, Y.: Developmental studies of work as a testbench of activity theory: In S. Chaiklin and J. Lave (Ed.), Understanding Practice: perspectives on activity and context, Cambridge, Cambridge University Press, 64-103. (1993)

18. Kuutti, K.: Activity Theory as a potential framework for human-computer interaction Research: In Nardi, B. (ed), Context and Consciousness. Chapter 2, 17-44. (1996)

19. Bødker, S.: Through the Interface: A Human Activity Approach to User Interface Design. Hillsdale, NJ: Lawrence Erlbaum (1991)

20. Qureshi S., Liu M., Vodel D.: A Grounded Theory Analysis of E-Collaboration Aspects of Distributed Project Management: In: Proceedings of the $38^{\text {th }}$ Hawaii International Conference on System Sciences, 1-10 (2005)

21. Allan G., (2003)

22. Strauss A. Corbin J.: Basics of Qualitative Research: Techniques and Procedures for Developing Grounded Theory. Thousand Oaks. London: Sage (1990)

23. Tang A., Boyle M., S. Greenberg: Display and Presence Disparity in Mixed Presence Groups: In: Proceedings of the $5^{\text {th }}$ Australasian User Interface Conference, Vol.28, 73-82, Dunedin, NZ (2004)

24. Flower, L. S., Hayes, J.R.: Problem-Solving Strategies and the Writing Process, College English, Vol. 39, No. 4, Stimulation Invention in Composition Courses, 449-461 (1977)

25. Posner, I.R., Baecker, R.M.: How People Write Together. In: Proceedings of $25^{\text {th }}$ Haiwaii International Conference on Computer System Sciences, Vol IV, 127-138 (1992)

26. Salas E. Fiore St.: Team Cognition: Understanding the Factors that Drive Processes and Performance. APA. New York. (2004) 